\title{
Viejos gringos: radicales norteamericanos en los años treinta y su visión de México*
}

\author{
Mauricio Tenorio \\ STANFORD UNIVERSITY
}

\begin{abstract}
El autor estudia el contexto histórico, específicamente el norteamericano, en que se formaron y realizaron su obra Joseph Freeman y Frank Tannenbaum.
\end{abstract}

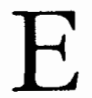

n 1920 George de Santayana en Character and opinion in the United States dejô dicho:

Idealism in the american...goes hand in hand with present contentment and with foresight of what the future very likely will actually bring. He is not a revolucionist; he believes he is already in the right track and moving toward an excellent destiny...

De esta forma, Santayana condensaba la esencia de la "tradición norteamerica-

- Versiones de este ensayo fueron leídas por Ariel Rodríguez, John Lear, Juan Martínez, Ariel y David Brading. A ellos agradezco sus lecturas, comentarios y desacuerdos. De todo lo de aquí culpa mía. na": la nación sin ancien regime, liberal, democrática, excepcional, individualista, la de la ética protestante y el espíritu pragmático. Sin embargo, para los años treinta, la depresión puso en duda el "excelente destino" de la nación americana. Entonces, la ciudad de Nueva York fue uno de los escenarios donde el idealismo que señalara Santayana fue cuestionado por la unión de dos formas de radicalismo: por un lado, la tradición populista norteamericana, de sólidas raíces rurales pero con expresiones urbanas; por otro, el radicalismo socialista.

Los intelectuales de Nueva York, hasta antes del surgimiento de la new leften los años sesenta, fueron considerados el radical momentum por excelencia de la 
historia norteamericana. Una de las expresiones de este momento fue el redescubrimiento de México. Una visión norteamericana diferente de las aproximaciones históricas tradicionales -por ejemplo, Bancroft y Presscott-y de las opiniones más o menos turísticas de viajeros norteamericanos.

En general, las variaciones de perspectiva responden mucho más a cambios en el ojo que ve que en el objeto observado. Este ensayo considera el redescubrimiento de México como resultado de varios fenómenos norteamericanos: de la respuesta intelectual a la depresión, de la construcción moderna del concepto de "tradición americana", y del proceso de profesionalización y academización del conocimiento en Estados Unidos. ${ }^{1}$

Si bien la visión norteamericana de México dice algo de la realidad mexicana, más habla sobre la propia realidad político-intelectual de Estados Unidos. Por ello, el redescubrimiento de México en los años treinta sirve como foco de análisis para entender el fracaso del socialismo marxista en la inteligencia norteamericana y la existencia de un radicalismo tan de suyo norteamericano como su supuesto excepcionalismo liberal; radicalismo que fue asumido, quizá sumi-

\footnotetext{
${ }^{1}$ El trabajo de Eugenia Meyer, uno de los pocos estudios mexicanos sobre la perspectiva norteamericana, sostiene opinión contraria. Parece ser que para la autora los cambios en México son los que explican los cambios de visión norteamericana. La autora no pone suficiente énfasis en el análisis de las condiciones domésticas (políticas e intelectuales) que condicionan las visiones norteamericanas. Por ello, por ejemplo, pierde de vista el porqué Tannenbaum menosprecia el desarrollo industrial para México (no ve la importancia de la influencia populista en esto) (véase Meyer, Conciencia bistórica, 1970, pp. 147-156). Sobre la noción de "creación" de la "tradición americana" véase Strout, Making, 1990, pp. 1-8. Sobre el "camino de dos vías" intelectual entre Estados Unidos y México, véase Brown "Exuberancia", 1968.
}

do, dentro de la misma presunción del excepcionalismo.

El redescubrimiento de México es inseparable del proceso norteamericano de autoconocimiento que fuera encabezado por la perspectiva ilustrada del norte. Esta visión desarrolló gradualmente la idea de la "primera nación nueva", exœpcional -en ambos sentidos: única y ejemplar-, liberal y democrática. Todos estos atributos contrastaban con la noción de un sur agrícola, atrasado, corrupto y populista.

Durante la crisis de los años treinta, las visiones casi oficiales, progresista-consensuales, fueron seriamente cuestionadas tanto en el norte como en lo que el historiador sureño C. Vann Woodward llamóel "nuevo sur". Las interpretaciones de fines del siglo Xxx hablaban de un sur despojado de su tradición populista, agraria, comunitaria y jeffersoniana en favor de un industrialismo y maquinismo a ultranza: un modernismo hamiltoniano. Vann Woodward, el más distinguido académico de la historia sureña, en los años sesenta al revisar su obra anterior, afirmó que

...lonecesarioera un tema en historia sureña y los medios para escribirlo de tal manera que expusiera lo que parecian ser las falacias, omisiones y largos silencios que caracterizaron a la escuela del "nuevosur". ${ }^{2}$

El revisionismo histórico-político de los años treinta volteó la vista hacia el sur de Estados Unidos y, por añadidura, a México. Caminos que mutuamente se nutren: por unlado, pensadores que observaron a

${ }^{2}$ C.V. Woodward considera como característica de la escuela historiográfica del nuevo sur "[...] la unidad de todos los blancos a través de la historia [...] el tema central de la superioridad blanca, la negación o el olvido de conflictos entre clases, razas y secciones, y el acompañamiento coral de progreso, prosperidad, conservadurismo político y reconciliación nacional", Woodward, Thinking back, 1988, p. 28. 
México influenciados por sus visiones del sur norteamericano, y a veces en busca de modelos revolucionarios; por otro, politi$\cos$ e intelectuales mexicanos que se apoyaron en esas visiones para elaborar sus. propias explicaciones de la época posrevolucionaria que no acababan de entender, así como sus discursos oficiales. ${ }^{3}$ A su vez, los historiadores norteamericanos de tradición radical, que escribieron historias de México, fueron posteriormente utilizados como modelos dentro de un nuevo momento revisionista y radical de la historiografia norteamericana en los años sesenta. ${ }^{4}$

El redescubrimiento de México en los años treinta fue el resultado histórico de la combinación de varios factores, circunstancias y tendencias. Entre estos factores quiero detenerme en dos claramente visibles: la influencia y transformación del populismo norteamericano, ${ }^{5}$ y el crecimien-

\footnotetext{
${ }^{3}$ Desde la visión.mercantilista de varios artistas mexicanos que vieron en ello la oportunidad de internacionalizarse, hasta el uso de los estudios norteamericanos sobre México para la construcción de la historiografia oficial (como hiciera la historiografia cardenista de los trabajos de Tannen. baum, lo cual no merma los méritos de los estudios de este último).

${ }^{4}$ Pienso, por ejemplo, en la influencia que F. Tannenbaum tuviera en libros tan trascendentales en la historiografia norteamericana como Genovese, Political economy, 1965.

${ }^{5}$ Este ensayo no apunta hacia un debate teórico sobre el populismo. El populismo ruso (agrariointelectual) constituye el prototipo de populismo, y aunque la comparación sin duda resultaría interesante, este trabajo toma la noción de populismo norteamericano, primero, como un fenómeno histórico (el movimiento del Partido del Pueblo), y luego como, a la manera de Wiles, un "síndrome" más que como una doctrina definida ("síndrome" cuyo contenido esencial es la idea general de que "...virtue resides in the simple people, who are the overwelming majority, and in their collective tradition..."). A lo largo de este ensayo se proponen algunas especificidades ideológicas básicas del populismo norteamericano, sin que esto quiera decir que en el trabajo de los intelectuales
}

to del socialismo norteamericano -más o menos marxista- en los años treinta. ${ }^{6}$ Para ello, primero, tomo como base de análisis laciudad de Nueva Yorkyel casoespecífico de dos intelectuales neoyorquinos que se interesaron por México en esos años: Joseph Freeman (1897-1965) y Frank 'Tannenbaum (1893-1969).' En segundo lugar, propongo una visión del desarrollo histórico del populismo y del socialismo norteamericanos, como tendencias político-intelectuales; interpretación que se deriva del análisis de la obra de los dos autores mencionados. Finalmente, explico la suerte que corrieron estas tendencias radicales que redescubrieron México.

\section{FREEMAN Y TANNENBAUM}

Democracy! As thoughvolcanoes ought know of democratic behavior... (p. 41)

My admiration goes to the US, for its many notable achievements, its conquest over nature rather than over man. But much of my love and hope goes out to the Latin World... (p. 361)

Carleton Beals (Mexican Maze, 1931).

inmigrantes esto no se haya mezclado con las ideas del populismo ruso y/o del anarco-sindicalismo. Entendido así, el populismo rebasa los límites agrarios y las posibilidades de una definición purista; véase el trabajo de Conovan, Populism, 1981.

${ }^{6}$ Es necesario, sin embargo, aclarar que este redescubrimiento se dio en dos áreas inseparables en su momento histórico: el arte y el análisis sociocultural. Pongo aquí especial énfasis en este último campo, sin dejar de reconocer lo fructífero que seria abordar el tema desde el campo del arte.

7 Carleton Beals, sin duda, sería el otro autor norteamericano de tradición populista que trató con detalle el caso de México. Sin embargo, intento tan sólo centrarme en la ciudad de Nueva York y su especial desarrollo intelectual, sin que ello quiera restar importancia a la experiencia de otras ciudades norteamericanas. Beals, en Berkeley, fue pilar de un periodismo radical; véase Britton, Carleton Beals, 1987. 
David Brading ha sugerido que en J. K. Turner, F. Tannenbaum, e incluso hasta en John Womack, existe una callada pero sólida influencia del populismo en "los comentarios norteamericanos sobre la naturaleza de la revolución mexicana". Esta sugerencia resulta interesante y provocativa e invita a analizar los distintos cauces seguidos por la vena populista.

John Reed, punto de referencia para los intelectuales neoyorquinos de principios de siglo, fue modelo de crítica y militancia. Reed sintetizó las tradiciones radicales norteamericanas en un contexto de fascinación por la revolución bolchevique, y a su vez presentó una nueva cara de México ante los norteamericanos: la del México revolucionario. En 1910, Reed llegó a Greenwich Village, destinada a ser la burbuja del radicalismo norteamericano hasta bien entrados los años cuarenta. Trabajó entonces para la principal publicación de la izquierda, la revista The Masses. Se introdujo, junto con otros intelectuales, dentro del círculo de la organización Industrial Workers of the World (Iww), muy activa entre 1914 y 1920 en innumerables huelgas textiles. En 1913 Reed viajó a México como corresponsal de guerra y un año después publicó Insurgent Mexico. Reedfue, pues, ejemplo de militancia e inteligencia para muchos jóvenes inmigrantes, entre ellos Frank Tannenbaum y Joseph Freeman, miembros, por cierto, del John Reed Club. ${ }^{8}$

En 1933 Frank Tannenbaum escribió:

\footnotetext{
${ }^{8}$ En los anoos veinte y treinta, además de Reed, estuvieron en México autores norteamericanos como Katherine Anne Porter, Hart Crane, John Dos Passos, George Biddle, Waldo Frank, Stuart Chase, William Spratling, Joseph Freeman y F. Tannenbaum. En estos años también, visita México el escritor inglés D. H. Lawrence (Theplumed serpent, 1926) y el francés A. Artaud ( $A$ u pays des tarabumaras, 1945). Véase Brown, "Exuberancia", 1968.
}

la revolución mexicana ha buscado traer a la arena política una tercera clase, y en consecuencia ha debilitado al menos temporalmente, sino es que ha completamente minado, la influencia de otras clases [...] La revolución mexicana fue anónima. Fue inicialmente la guerra de la gente común [...] Ningún partido organizador la presidió en su nacimiento [...] el programa de la revolución aún está siendo escrito.

Cuatro años más tarde, Joseph Freeman, de viaje por el México cardenista, afirmó:

mucho antes que con la revolución rusa, contrajimos un serio deber con la revolución mexicana y con el pueblo de México. Los nombres de Felipe Carrillo Puerto y Emiliano Zapata nos han ayudado a comprender y a amar más a Lenin. Cuando los reaccionarios de mi país insisten en decirnos que la idea revolucionaria es una importación rusa, les contestamos que muchos años antes del gran ejemplo ruso tuvimos el ejemplo de los libertadores mexicanos.

En efecto, los comentarios sobre México de los intelectuales néoyorquinos de los años treinta, por un lado, fueron hechos desde y para reforzar el afán populista más o menos revolucionario, y por otro, sirvieron al deseo de construir un socialismo marxista en Estados Unidos.?

En 1904, entre las muchas familias de origen judío que emigraron a Estados

? Por supuesto Joseph Freeman y Frank Tannenbaum son autores incompatibles a primera vista, tanto por la distinta profundidad en su tratamiento de México, como por la desigual trascendencia tenida dentro de la propia Norteamérica. Empero, los dos autores pertenecen aproximadamente a igual generación; ambos, aunque con diferente agudeza, estuvieron interesados en México durante los años treinta; ambos son de alguna manera parte de los New York intellectuals. 
Unidos entre 1890 y 1920 , llegaron a la costa este la de Tannenbaum y la de Freeman. Los Tannenbaum de procedencia austriaca, los Freeman de origen ruso. Los Tannenbaum eran de extracción campesina y se establecieron en una granja en Berkshires en el estado de Massachusetts. Los Freeman provenían de una villa ucraniana, Poltova, y llegaron a la ciudad de Nueva York. Frank Tannenbaum, en la adolescencia, emigró a esta ciudad, aunque sin desvincularse del todo de la granja paterna. Se hizo militante de la IWW y participó en varias protestas, una de las cuales le costó un año y meses de cárcel.

Freeman pasó sus años de juventud en los guetos judíos de Nueva York, barrios pobres pero en rápido ascenso. Como más tarde hará Tannenbaum, Freeman entró a la universidad donde combinó su actividad militante con la que finalmente fue su vocación: la de crítico, periodista y poeta. Participó tanto en The Masses como posteriormente en la vistosa revista de la izquierda norteamericana The New Masses; también tomó parte en la fundación de la célebre revista de la entonces izquierda, hoy neoderecha: Partisan Review.

Después de escribir libros sobre las condiciones y derechos obreros, la situación del sistema penitenciario de Estados Unidos, y después de viajar por toda la unión americana, Tannenbaum arribó a México entre 1922 y 1923 como corresponsal de las revistas Century Magazine y Survey Grapbic, de tradición liberal humanista. En 1924 coordinó un número, dedicado a México, de Survey Grapbic, con artículos de otro autor norteamericano de tradición populista, Carleton Beals, y de'mexicanos, entre otros, Carrillo Puerto y Diego Rivera. Son célebres sus dos estudios sobre México elaborados alrededor de los treinta: Mexican agra- rian revolution (1928) y Peace by revolution: Mexico after 1910 (1933). Desde entonces, Tannenbaum dedicó su vida académica al estudio de México y Latinoamérica y llegó a formar una escuela de latin americanists en la Universidad de Columbia, Nueva York. En los estudios anglosajones de Latinoamérica es aún visible la herencia de Tannenbaum.

Freeman, por su parte, conoce México primero en 1926 como corresponsal nada menos que de la agencia TAss, y posteriormente en 1937 como miembro, junto con Waldo Frank, de la delegación norteamericana al Congreso de Escritores y Artistas Revolucionarios celebrado en México en enero de 1937. También asistió a este congreso como enviado de The New Masses y promotor de la creación del Frente Popular, tanto en Estados Unidos como en México. Fue un gran patrocinador del "realismo socialista" norteamericano con libros como Proletarian literature in the United States. An anthology (193?) y con sus estudios de literatura rusa. Antes, en 1925, trató el caso de México y la "explotación imperial" norteamericana -en especial con respecto a las inversiones norteamericanas y británicas en petróleo- en Dollar diplomacy: a study in american imperialism en colaboración con Scott Nearing. Ahí, Freeman advertía, inspirado por el artículo de Pereyra "El mito de Monroe":

los débiles países vecinos en los cuales existen importantes inversiones norteamericanas deben esperar que sus problemas internos estén dominados por el gobierno de Estados Unidos cuando esa dominación parezca ventajosa a los intereses norteamericanos.

La historiografia mexicana y la norteamericana están necesitadas de un retra-

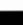




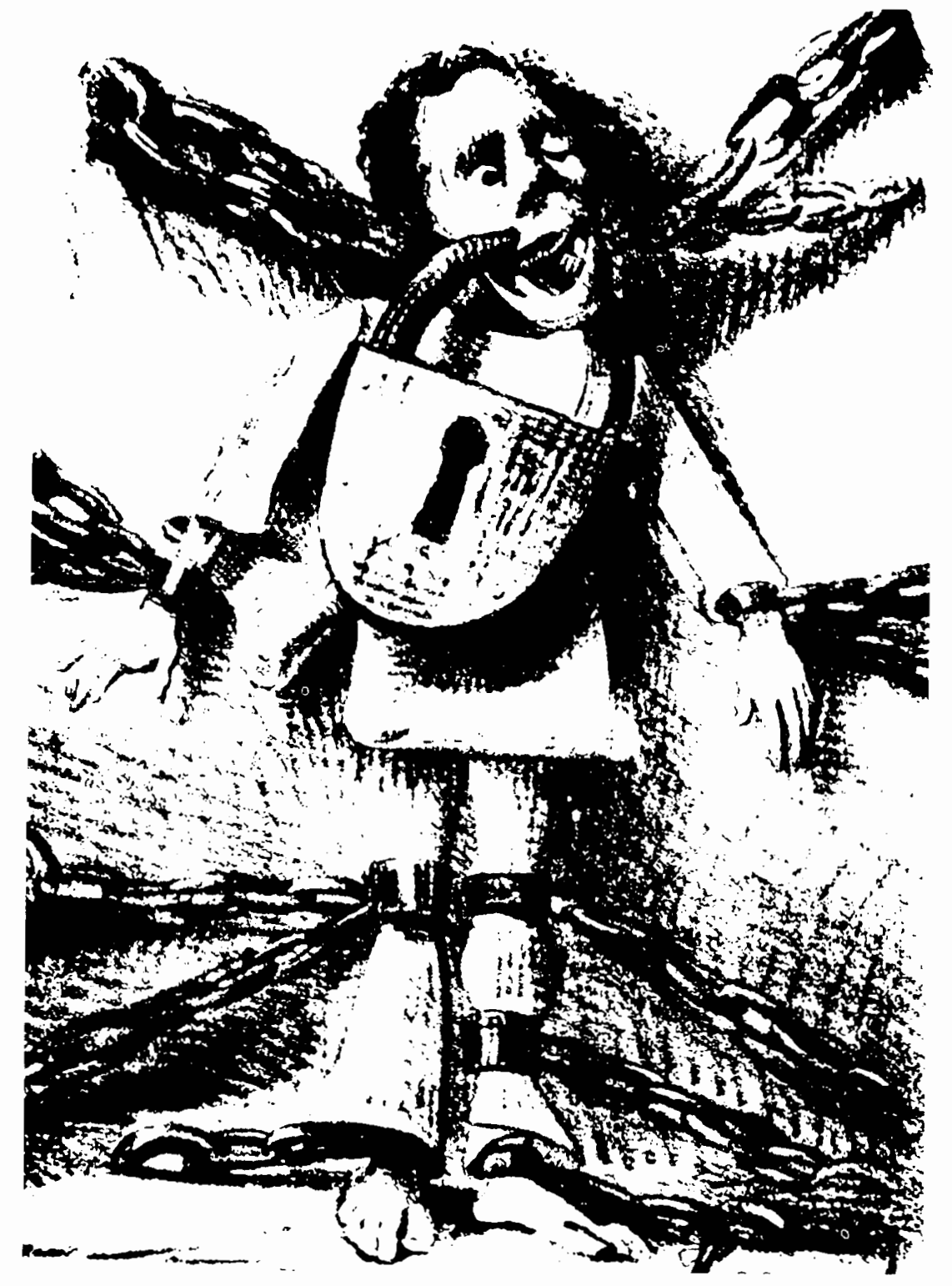


to social e intelectual de Frank Tannenbaum. Personalidad sui generis, construida de sólida militancia sindicalista, conocimiento profundo de la realidad obrera y campesina de Estados Unidos, e influido por el anarco-sindicalismo, el populismo, el americanismo del tipo del New Deal e incluso por las corrientes psicoanalíticas freudianas muy sonadas en las primeras tres décadas del siglo $\mathrm{xX} .{ }^{10}$ Tannenbaum hizo sus estudios de México y América Latina intentando no alejarse del empirismo propio de la academia norteamericana, aunque, como hace ver David Brading, su manejo de la información censal dejó mucho que desear. Con todo, sus inspiraciones teóricopolíticas dieron a sus estudios una agudeza analítica que retomará la misma academia norteamericana durante una nueva época de autocuestionamiento: los años sesenta, cuando se generalizó el descontento de las aproximaciones "científicas" que hacianénfasis en el consenso liberal y las continuidades antes que los rompimientos. Tannenbaum puso en circulación la noción de revolución popular y corporativismo para referirse a México. Por supuesto, su experiencia sindicalista dentro del New Deal así como su vivencia de lo que Alan Trachtenberg llama "la incorporación cultural y económica de América" -Estados Unidos- le sirvieron de útiles puntos de referencia. A su vez, como sostiene Brading, los trabajos de Molina Enríquez y Luis W. Orozco fueron importantes influencias mexicanas que indirectamente -vía Tannenbaum - influenciaron a la historiografía norteamericana.

Antes de que se satanizara al corpora-

${ }^{10}$ Como es claramente visible en sus estudios sobre las causas de la existencia del Ku-klux-klan en el sur de Estados Unidos. Véase Tannenbaum, Darkers phases, 1924. tivismo fascista, y previamente a que se hablara del fracaso del corporativismo norteamericano -el New Deat, Tannenbaum se refirió al corporativismo mexicano como una conformación histórica, una forma autóctona de respuesta política y humanitaria a los problemas nacionales específicos. Así, fue conocida su gran amistad con Lázaro Cárdenas. ${ }^{11}$ México, creyó Tannenbaum, contenía todavía la esperanza perdida ya para los populistas de los años noventa del siglo XIX y para los radicales neoyorquinos; la comunidad y la cooperación podrían salvarse, y entonces, sostiene Tannenbaum en Peace by revolution,

México se caracterizaría por miles de pequeñas comunidades poseedoras de sus tierras en forma semicomunal, trabajándolas colectivamente, con una escuela en el centro, con un alto grado de cooperación comunitaria [...], con las bases de un gobiemodemocráticodescansando en una comunidad unificada.

En su socialización política, Frank Tannenbaum encontró una manera de expresar sus concepciones "propueblo" en las ideas libertarias del anarquismo norteamericano que aprendió en la Escuela Moderna nocturna establecida en Nueva York por personas como Emma Goldman -siguiendo el modelo de la Escuela Moderna del catalán F. Ferrer i

${ }^{11}$ Como emblemático de sus concepciones del especial sistema mexicano, es revelador el cap. 14 de Peace by revolution, pp. 161-174 ("Emergence of a program") y las pp. 201-203 de Mexican agrarian recolution. En sus análisis de la nueva tenencia de la tierra, de las nuevas leyes laborales y de la Constitución, Tannenbaum despliega su concepción del corporativismo mexicano como una solución original a problemas específicos; solución que se explica por la propia historia mexicana y que fue, según Tannenbaum, adelantada para su tiempo (sobre esta concepción véase también Tannenbaum, The balance, 1969, pp. 1-26). 
Guàrdia. Se trata de la Emma Goldman símbolo de una época en la cual, como afirmara Joseph Freeman en sus memorias

...los nombres de Joe Ettor y Arturo Giovannitti, líderes de la huelga textil de Lawrence, se volvieron palabras domésticas, y cuando Emma Goldman pudollenar centros de mítines en cualquier ciudad con discursos sobre anarquismo, amor libre y Shakespeare.

$Y$ es el Tannenbaum de quien posteriormente Freeman guardó, según narra, el recuerdo imborrable de un 4 de marzo de 1914 en Rutgers Square donde aquél pronunció un discurso en favor de los desempleados yen contra del capitalismo: "Somos miembros de la clase trabajadora. Todo en esta ciudad fue creado por nuestras manos o por las manos de nuestros hermanos y hermanas." Un ejemplo para una generación de inmigrantes judíos, como Freeman, que intentaban al mismo tiempo entender $y$ transformar su mundo.

Joseph Freeman también quiso rescatar la sensación de comunidad, aunque de manera más doctrinariamente socialista. Junto con el grupo de The New Masses se dio a la tarea de crear la versión norteamericana del realismo socialista con variadas dosis de estalinismo. Su American testament (1936), es el testimonio de cómo un inmigrante judío se acercó al socialismo. Un camino de varios cauces, uno de ellos el radicalismo periodístico en busca de modelos revolucionarios para el oficio de crítico y poeta. En 1937, Freeman escribió desde México al editor de The New Masses:

si después de la guerra los intelectuales norteamericanos se encontraban en el café de la Rotonda, y a principio de los treinta en la Plaza Roja [...] ahora ese encuentro tiene lugar en el Palacio de Bellas Artes. Si el mismo tipo de intelectuales ahora viene a México es probablemente porque en su fase presente de simpatia socialista, encuentran más cerca de su propio país, una tierra donde arte y política se mueven en el nivel más cercano a su integración [...].

Esta fue la visión de México de la izquierda norteamericana doctrinaria.

La visión comunista de Freeman preveía el advenimiento de la revolución y advertía los peligros del imperialismo. Por el contrario, la más compleja perspectiva de Tannenbaum tenía un acento menos internacionalista. No olvidaba la experiencia norteamericana que tan bien conocía: en 1921 en su libro The labor movement Tannenbaum creía que la transformación revolucionaria iba a llegar a Estados Unidos como producto de la sindicalización imparable, pero señalaba que, a la larga, traería consecuencias conservadoras al estabilizar y ordenar el sistema social, porque esto acabaría por hacer menos ásperos los conflictos y por crear un. verdadera comunidad. Igualmente, en 1933 Tannenbaum advertía en México la posibilidad de la derrota de la comunidad; creía que en ese caso la respuesta sería la violencia continua: "el pueblo está tomando su oportunidad instintiva y directamente, aunque sin grandes metas excepto tierra, excepto libertad, excepto paz interna". Para México, el triunfo de la comunidad agraria era el triunfo de la revolución y por tanto la pacificación y el regreso a las antiguas formas de vida. En Mexico, struggle for peace and bread (1950), Tannenbaum fue todavía más fiel a su vena populista y anarco-sindicalista, de acento rural antes que industrial:

Si México fuera sabio, la industria mexicana sería aceptada como un complemento de una economía agrícola, y el énfasis 
estaría en la maravillosa energía y los poderes de cohesión de la comunidad rural [...] México, estoy convencido, puede alcanzar su completo desarrollo cultural y económico sólo si adopta una política intrínseca a su propio genio: una que enriquezca a la comunidad local.

\section{RADIX MALORUM EST POPULISMUS}

En 1895 apareció en México el folleto de Antonio Muñoz Navarro: Del populismo: breve exposicion y examen de un gran proyecto de economía politica para una nueva sociedad norteamericana, donde su autor explicó al público mexicano lo que sucedía en Estados Unidos con aquellos que él llamó "demófilos": los que buscaban no sólo el control popular del gobierno, sino la creación de una "república universal". ${ }^{12}$ Por osado que parezca, Muñoz Navarro dio a conocer a los porfiristas la ideología política de amplios sectores de obreros y agricultores norteamericanos que a finales del siglo XIX enfrentaron el desmedido industrialismo norteamericano. Ni qué decirlo: el llamado de Muñoz Navarro tuvo poco eco en las elites porfirianas que $\mathrm{si}$ admiraban algo de Norteamérica, era su progreso industrial; los detalles y mecanismos de la democracia los tenían sin cuidado. En Estados Unidos, sin embargo, el populismo fue un movimiento so-

${ }^{12}$ La obra estaba dedicada al "ilustre maestro" Emilio Castelar. En ella, Muñoz Navarro hablaba de una "república universal" cuyo primer estado sería la unificación "populista" de México y Estados Unidos, unión de la que sería presidente Porfirio Díaz y vicepresidente el senador por Nevada William M. Stewart. El objetivo de una unión populista seria "encomendarle" al gobierno "de luego a luego", "la antigua práctica natural" de "cuidar los intereses generales de la sociedad o comunidad", de velar de que "si bien siempre habrá pobres y ricos [...] nunca debe haber opulentos y miserables"; véase Muñoz Navarro, Del populismo, 1895. cial de importancia y una cultura política cuya trascendencia es aún motivo de debate.

El populismo como fenómeno histórico fue un movimiento fundamentalmente rural. Con todo, como "síndrome" político-intelectual tuvo su corolario urbano: lo que W. Susman llama "americanismo"; es decir, un reformismo social norteamericano como sustituto de un "consciente socialismo". La socialización de las cosas antes que de Estados Unidos; la idea de una nación comandada por una nueva clase media de profesionales disciplinados y científicos. En suma, el norteamericano fue un reformismo filantrópico y más o menos populista que no se oponía, sino que daba énfasis a la eficiencia en la producción.

Tanto el populismo como el americanismo son tradiciones radicales, aunque de consecuencias conservadoras, quizá de igual naturaleza pero pertenecientes a distintos contextos, y ambas tuvieron profundas raices religiosas. A la larga, acabaron por nutrirse mutuamente. El populismo fue una manifestación del "radicalismo norteamericano que ni siquiera los más agudos oponentes pudieron estigmatizar como, 'extranjero' ". ${ }^{13} \mathrm{Su}$ expresión urbana, el americanismo reformista, se mezcló con el socialismo marxista de los años treinta, y así quedó marcado como alien ideology. Reformismo y socialismo terminaron dañados, uno atacado por socialista, el otro minado en su interior por el reformismo no revolucionario del americanismo. ${ }^{14}$

${ }^{13}$ Woodward, "The populist", 1968.

${ }^{14}$ Por ello, por ejemplo, en los años sesenta decía W. Susman, miembrodela new left académica: "hemos sido realmente sabios en nuestro afán de un americanismo en un esfuerzo de capturarlo en lugar del socialismo, o el mismo americanismo acabó capturándonos porque no hemos sido to suficientemente autoconscientes y autocríticos" (Susman, Culture as bistory, 1984, p. 215).

\section{1}


Para historiadores como Frank Tannenbaum, el populismo impuso su influencia directa por su triple carácter: por haber sido movimiento social, por ser tradición político-intelectual y por constituir un tema de análisis histórico social de los académicos e intelectuales norteamericanos. En efecto, Tannenbaum conoció y vivió la experiencia agrícola norteamericana de finales del siglo $\mathrm{XIX}$ y principios del xx. Entonces, el acelerado desarrollo y crecimiento económico de Estados Unidos estaba transformando rápidamente las tradicionales formas agrícolas de vida y producción. Las tradiciones de las comunidades autónomas de colonos pioneros, y las costumbres del creciente número de inmigrantes, fueron mezcladas y transformadas por una economía cada vez más industrial y capitalizada. Se sabía ya perdida la comunidad pionera, democrática y utópica, al menos en la mayor parte de Nueva Inglaterra. Además a finales del siglo XIX mientras que en el norte industrial crecían las industrias manufactureras y la agricultura comercial, la mayoría de los granjeros del oeste y del sur estaban endeudados debido, según su perspectiva, a la introducción masiva de los ferrocarriles, el intermediarismo, la usura de los bancos, en fin, debido a la mano negra de los big businesses. En esta época empezaron a surgir organizaciones que buscaron "devolver al pueblo el control de la democracia". Organizaciones como Patrons of Husbandry (1867), conocida como el movimiento grange. Esta organización sacó a la luz varios partidos agrarios del medio oeste norteamericano. Después surgieron movimientos como los greenback (ca. 1873) el cual también se disolvió aunque logró tener alguna actividad partidista. A raíz de estas organizaciones, surgieron alianzas agrícolas que a la larga dieron lugar a la creación, en el estado de Kansas, del Partido del Pueblo (1890).

La historiografia norteamericana considera esta época como el periodo populista. En busca de una economía cooperativa, los populistas norteamericanos de los años noventa del siglo XIX deseaban el control estatal de los ferrocarriles, los bancos, los correos, la prohibición de posesión de tierras a extranjeros, la restricción de la inmigración.

La estrategia política de los populistas sureños estaba basada en combinaciones y alianzas a lo largo de líneas regionales, de clase y raciales: una alianza entre el sur y el oeste; una combinación de granjeros y trabajadores de las fábricas y la ciudad; y una unión política con los granjeros y obreros negros dentro del mismo sur. ${ }^{15}$

Su más sonada bandera fue el ataque a los industriales, capitalistas y financieros urbanos del norte y de las ciudades del sur. Sin embargo, los populistas no estuvieron exentos de connotaciones racistas y sus uniones con las organizaciones no blancas siempre fueron estratégicas. La caída del movimiento populista es comúnmente ubicada en la elección de 1896 , momento en que los populistas se dividieron ante la opción de apoyar al candidato demócrata William J. Bryan. La historiografia tradicional norteamericana narra cómo los populistas apoyaron a Bryan (quien fue derrotado), y cómo el triunfo de McKinley, candidato republicano, constituyó el inicio de un periodo republicano partidario del liberalismo económico y de los intereses urbanoindustriales. En suma, las historias patrias de Norteamérica consideran que este movimiento fue la última acometida del radicalismo agrario en contra del in-

\footnotetext{
is Woodward, The origins, 1971, p. 101.
} 
dustrialismo capitalista rampante: última carcajada del fantasma jeffersoniano.

La historiografia norteamericana debate sobre los verdaderos alcances del populismo, baste aquí señalar que durante los años treinta surge un particular interés por estudiar el populismo-sintomático de esto es el influyente estudio de John Hicks The populist revolt, 1931. Coincidentemente, resucitaba la conciencia sobre las distintas "secciones" que conformaban Estados Unidos, ${ }^{16}$ y se redescubrió México como foco revolucionario de centenaria tradición comunitaria y como ejemplo de transformación agraria.

Dentro de la historiografia norteamericana, el populismo parece haber cumplido ya un ciclo de interpretación. A principios de los sesenta Woodward resumió así las viejas, entonces nuevas, interpretaciones: "la vieja interpretación algunas veces se acerca a la afirmación de que el populismo es la raíz de todo bien en la democracia, en tanto que la nueva (1960) sugiere que el populismo es la raíz de todo mal". ${ }^{17}$ En 1983 , Goodwyn regresó al populismo, apoyándose en una rigurosa investigación, a la interpretación populista del populismo: la última oportunidad del pueblo norteamericano para obtener una verdadera democracia guiada por el pueblo y no por los mecanismos de las grandes corporaciones y el clientelismo.

El reconocimiento de la tendencia populista en la cultura política y en la tradición intelectual norteamericana fue determinado por aquella máxima posmacarthista que a manera de burla se le ocurriera a Woodward: Radix malonum est po-

${ }^{16}$ No hay mejor ejemplo de esto que el estudio de J. K. Turner, elclásico de la historiografía norteamericana de fin-de-siècle, The significance, 1932.

17 Woodward, Thinking back, 1988, p. 135. pulismus. En efecto, durante la posguerra los marxistas desencantados y los liberales conservadores buscaron explicaciones a las irracionalidades del macarthismo y al horror a las masas que explicablemente la guerra y el holocausto habían acentuado. Así, hicieron de la tradición populista un útil chivo expiatorio. A ella culparon de las manías racistas, del antisemitismo, del antiintelectualismo y del espíritu de linchamiento. Como fenómeno histórico (rural) e inspiración política (rural y urbana), el populismo fue desterrado a la jaula de lo indeseable. Entonces, se le consideró el nutriente fundamental del nazismo y del bolchevismo. Autores como Talcott Parsons, Edward A. Shils, S. Martin Lipset, Daniel Bell y el historiador Richard Hofstadter, fueron baluartes del desprestigio político-intelectual del populismo. La influyente revisión histórica del populismo llevada a cabo por este último autor, colega de cátedra de F. Tannenbaum, contribuyó al surgimiento de esta interpretación. Hoftstadter vio en el populismo una ideología tradicionalista y ruralista que no comprendióeldesarrollo norteamericano, y que al perder, en realidad ganó su entrada a la América democrática y próspera, pues, a pesar de todo, es un pensamiento que sobrevive en "la tradición americana". En especial, Hofstadter resaltó lo antisemítico del populismo. En suma, por un lado este autor hizo ver que el populismo no fue un mero movimiento rural sino una arraigada tendencia de la "tradición norteamericana" y, por otro, dio origen a la batalla historiográfica entre propopulistas $\mathrm{y}$ antipopulistas que, como muestra Peter Novick, traía a cuento problemas raciales dentro de la academia, pues tenía mucho de autobiográfico para la comunidad de historiadores judio-norteamericanos. ${ }^{18}$

18 Véase Novick, That noble dream, 1988, pp. 337-341. 
Lo esencial del populismo es el cuestionamiento que hace a la concepción predominante de lo que es la "tradición americana". Se trató de una verdadera tradición radical de origen históricamente rural, pero que se mezcló con los fenómenos urbanos y con las corrientes del pensamiento reformista. Fue una de las caras del reformismo norteamericano cuya expresión única no es el movimiento populista de los años noventa del siglo pasado, sino que en el ambiente urbano tuvo distintas manifestaciones, como el pensamiento utópico y antidarwinista social de Henry George y Edward Bellamy. El populismo constituyó el ingrediente obligado de la "conciencia de clase" de los inmigrantes. Antes que ninguna, si alguna "conciencia de clase" tuvieron estos trabajadores, derivó de las tradiciones populistas y comunitarias del campo norteamericano o de las regiones rurales de donde procedían.

Se puede reducir al mínimo esta tradición populista distinguiendo al menos tres contenidos fundamentales: $a$ ) uno casi ético-bucólico: el bienestar del pueblo, entendido como comunidad cotidianamente visible; un criterio que guía toda acción política o económica. Esto incluía el ingrediente más o menos democrático sustentado en la noción del campo y del hombre como fuentes de la riqueza -la cual debe regresar al hombre y al campo-, yen la capacidad de autogobernarse. De ahí, por ejemplo, la exigencia de ir contra la corrupción de los grandes negocios y de someter a control democrático a un Estado dominado por las corporaciones económicas. b) Uno utópico: la lucha por la América popular, la verdadera. Una noción de identidad que, con el supuesto de que todos los ciudadanos comparten su membresía a un cuerpo orgánico -la "nación del pueblo"-, mantenía en pie "la espera de la utopía dentro de la vida política norteamericana". ${ }^{19}$ c) Como consecuencia, una predisposición hacia las ideas libertadoras e igualitarias dentro de la comunidad -lo cual no elimina tendencias racistas o excluyentes hacia afuera de la comunidad. No extraña, pues, los destinos en que encontró vida esta tradición populista: en la constante lucha local por el control democrático directo -que se refleja en el alto nivel local de auto-gobierno de la sociedad norteamericana-, en el estado benefactor corporativista (New Deal), y en una suerte de concepciones ideológicas más o menos de izquierda, pero que culturalmente protegen la idea de pueblo, y sustentan el concepto de comunidad y el sentido de fraternidad.

Para finales de siglo, los centros urbanos como Nueva York hacían ver que la afirmación del excepcionalismo norteamericano no fue un pacífico y etéreo consenso natural en los valores pragmáticos y democrático-burgueses. Que el espíritu norteamericano era una tradiciôn conflictiva en constante autoproducción. Así, la tradición populista sobrevivía en las ciudades cada vez más pobladas por inmigraciones internas y de extranjeros, y con un impresionante crecimiento de la clase obrera. Aunque la mayoría de la inteligencia neoyorquina, sostiene Woodward, "nunca se aventuró al sur del Potomac, y si lo hicieron, su sur era Miami", la tradición populista estuvo presente en Nueva York a través de su mutua influencia con las ideas anarcosindicalistas, reformistas y socialistas. Esta combinación fue visible en la creciente ola de protestas obreras, así como en la obra de ciertos escritores neoyorquinos que sí vieron hacia el sur y hacia the other balf urbana, como Tannenbaum. Y en esto México fue inventado como un

\footnotetext{
${ }^{19}$ Goodwyn, The populist, 1978, p. 2.
} 
ejemplo idealizado de lucha popular y vida comunitaria: lugar de elaboración de la utopía... un sano complemento para la nación norteamericana que creía cumplida la utopía.

III. NUEVA YORK Y EL RADICALISMO DE LOS AÑOS TREINTA

El radical momentum de los años treinta no fue la simple imposición de una ideología extranjera, sino un complejo proceso de acoplamiento y traducción de las tradiciones radicales autóctonas a un discurso revolucionario universal: el socialismo internacional. Como los populistas en Rusia, los intelectuales de Nueva York -populistas, socialistas y anarquistastrataron de traducir el marxismo al lenguaje norteamericano.

En la ciudad que a Joseph Freeman y a Frank Tannenbaum les tocó vivir confluyeron una serie de fenómenos: crecimiento de la clase obrera, de la inmigración, deterioro del nivel de vida, estallamiento de huelgas, crecimiento del poder de los grandes consorcios y, finalmente, la depresión. Durante las primeras décadas del siglo $\mathrm{XX}$ se dio una gran inmigración judía del este de Europa a la costa este de Estados Unidos. Estos inmigrantes fueron sustento del radicalismo neoyorquino de los años treinta, no nada más por habilitar la discusión del socialismo internacional, sino por redirigir y absorber las formas autóctonas de radicalismo y el total de la tradición norteamericana. Entre 1901 y 1914 casi 9000000 de europeos (entre italianos, judios y eslavos) emigraron a Estados Unidos. La mayoría de ellos era de extracción campesina, aunque sirvieron de mano de obra para el acelerado proceso de industrialización. El radicalismo de los judíos neoyorquinos no fue una mera ideología importada, alien al etbos norteamericano, como con frecuencia se afirma dentro de la historiografia, sino que fue una manera particular de respuesta a lo que se vivía: la explotación y miseria que Jacob Riis, él mismo un inmigrante, periodísticamente describió en How the other half lives (1890). Para estos inmigrantes, Nueva York significó no sólo un espacio para el acoplamiento y la coincidencia de tendencias intelectuales, sino también una realidad que exigió confrontar sueños: el sueño americano frente a la realidad de pobreza de los guetos del Greenwich Village o del Bronx judío. O el sueño judío kol yisroel khaverim (todos los judíos son camaradas), frente a la realidad de serias divisiones internas dentro de su comunidad. Por ejemplo, en sus memorias, Joseph Freeman describe lo impresionante que le resúltó presenciar una huelga en la cual patrones judíos contrataban matones italianos para asesinar trabajadores judíos.

En términos de Nueva York y sus intelectuales, los años treinta siguen siendo un periodo harto debatido por los analistas norteamericanos. Para unos los años treinta fueron el momento donde los intelectuales experimentaron las consecuencias de "la trágica inocencia". Desde entonces aprendieron a evitar cualquier ideología (vg. Susman, Higham). Para otros, la década de los treinta fue un ejemplo de la lucha infructuosa por lograr un movimiento socialista no estalinista, una izquierda independiente y en concordancia con la experiencia norteamericana; una lucha que no ha terminado (vg. Wald). Para otros más, los treinta constituyeron un simple radical momentum que no percibió hasta qué punto estaba lleno de "tradición norteamericana" y que finalmente acabo por entrar al cauce 
de esa tradición (vg. Pells). Con todo, predomina la afirmación excepcional del desarrollo capitalista y liberal, naturalmente antirradical, de Estados Unidos.

Treinta años después de que Werner Sombart publicara Warum gibt es in den vereinigten staaten keinen sozialismus (1906) (¿Por qué no existe un movimiento socialista en los Estados Unidos?) un cúmulo de intelectuales como Joseph Freeman contradijeron las predicciones. Lo excepcional de Norteamérica, a este respecto, ha sido señalado innumerables veces. ${ }^{20}$ Sin embargo, lo cierto es que Estados Unidos tuvo de todo en el espectro de los radicalismos, por ello, la pregunta -según afirma I. Howe- no es el porqué de la radicalización de unos, sino el porqué de la no radicalización de todos. Estados Unidos contó con movimientos socialistas, formas locales de radicalismo $\mathrm{y}$, por supuesto, con una inteligencia socialista en el sentido doctrinario. En gran medida eso fueron los intelectuales de Nueva York, al menos hasta mediados de los años cuarenta. Además del pensamiento socialista de los intelectuales de Nueva York, existieron movimientos como el encabezado porE. V. Debs dentro del partido socialista. En 1912, este partido alcanzó su mejor resultado: casi 1000000 de votos.

La izquierda en que Freeman y

${ }^{20}$ En ocasiones a la manera de D. Bell, quien sostiene que no hubo excepción porque no hay regla; ¿por qué tenía que haber socialismo en Estados Unidos? Defensa máxima del excepcional ismo, pues, cierto, no hay reglas en la historia, y cada proceso es, hasta determinado punto, único, no hay línea de desarrollo progresivo, pero si hay tendencias "epocales". Y en esa época, como dice E. Hobsbawm "no importa lo que los historiadores puedan establecer en retrospectiva, para los contemporáneos la masa de trabajadores era grande, sin duda alguna estaba creciendo, y lanzaba una sombra oscura sobre el orden establecido de la sociedad y la política" (véase Bell, The windding, 1980; Hobsbawm, The age, 1987).
Tannenbaum se movian estaba profundamente dividida. Durante la primera parte de los años treinta, el Partido Comunista constituía la fracción de la izquierda ligada al estalinismo; del otro lado estaban las organizaciones igualmente de izquierda pero no estalinista The American Workers Party, The Communist Party Opossition y The Communist League of America (de orientación trotskista, dirigida por gente como Max Shachtman y James P. Cannon). A mediados de los treinta, con el agudizamiento del conflicto entre estalinistas y trotskistas, el trotskismo atrajo a varios intelectuales, agudizando más las divisiones de la izquierda norteamericana. De parte de los intelectuales hubo, sin embargo, intentos de unificación para formar el Frente Popular. En abril de 1935, se llevó a cabo en Nueva York el primer Congreso de Escritores Norteamericanos, organizado por el Partido Comunista. A él asistieron además de Joseph Freeman, intelectuales de la altura de Malcom Cowley, Waldo Frank, John Dos Passos y Langston Hughes, entre otros.

El socialismo marxista también parece un camino de dos vías entre México y Estados Unidos: en 1937 se celebró en México el Congreso de Intelectuales y Artistas, a él asistieron Waldo Frank y Joseph Freeman. Su presencia en México causó gran revuelo en la izquierda oficial y no oficial. El gobierno cardenista hizo mucha publicidad a su visita y los llevó a admirar los cambios que el país estaba experimentando, ${ }^{21}$ como si la presencia

${ }^{21}$ Esto movió a la punzante pluma de Salvador Novo a afirmar que "a la comitiva del presidente se agregó Waldo Frank, escritor yanqui que hace poco sorprendió a un grupo anónimo de escritores inéditos" (Novo, La vida, 1964, p. 320). Se refería a la polémica despertada en publicaciones como $E l$ Nacionaly ElMacbete, polémica iniciada por Frank al comparar la religión con el marxismo. W. Frank 
de Frank y Freeman por ser socialistas, pero más por ser norteamericanos, legitimara la obra cardenista.

Así pues, las tradiciones radicales norteamericanas y los avatares del socialismo internacional encontraron formas de coexistir. Sin embargo, con frecuencia, más que hablar de la naturaleza del radicalismo norteamericano, se habla de lo alejados que estuvieron los radicales años treinta de la "tradición norteamericana". Richard Pells mantiene que en esa época los intelectuales radicales eran al mismo tiempo críticos y sustentadores de los valores y sueños americanos tradicionales. Su interpretación, abarcante aunque poco profunda, es emblemática de esta frecuente visión. Así, los supuestamente radicales eran en realidad casi inconscientemente conservadores. Inmersos en la depresión, los intelectuales abrazaron la promesa radical y la mezclaron con los intrínsecos "valores americanos". Empero, fracasaron en producir una nueva síntesis ideológica que pudiera sustituir la síntesis llevada a cabo por la llamada era progresista en la "época dorada" ( $c a$. 1890-1920). Se trata de una cronología político-intelectual más o menos aceptada: la del llamado progresismo de los años veinte, ambivalente pero ideológicamente funcional síntesis de valores tradicionales y nuevas circunstancias. ${ }^{22}$ Es un

fue un autor importante durante una época dentro del ambiente intelectual norteamericano que posteriormente quedó olvidado, como lo muestra el hecho de que sus memorias tuvieron dificultades para aparecer en inglés (de hecho, ignoro si en realidad existe hoy versión en inglés de ellas). Véase al respecto, introducción de A. Trachtemberg y Lewis Mumford a las memorias de W. Frank publicadas en castellano (Buenos Aires, 1975).

${ }^{22}$ Influyentes autores como Croly, The promise, 1912, Wyck Brooks o historiadores como Beard, The rise of american, 1927 y el filósofo del pragmatismo John Dewey pueden, no obstante sus diferencias, ejemplificar la naturaleza de este periodo. periodo durante el cual los intelectuales restablecieron para los Estados Unidos del siglo xx la fe en la era de la ilustración, en la historia como un progreso interdependiente entre razón y sociedad. De ahí al momento radical (ca. 1933-39), y de éste al conservadurismo (cuyo inicio es ubicable entre 1939-41).

Resulta discutible esta concepción guiada por el apego a un concepto más bien huidizo de "tradición y valores americanos". Sin embargo es analíticamente útil para distinguir que dentro del conocido como radical momentum, las formas autóctonas de radicalismo entraron en compleja relación, por una parte, con las ideas socialista y libertarias de la época $y$, por otra, con el proceso de institucionalización del conocimiento que se había iniciado en Estados Unidos a principios de siglo. En el redescubrimiento norteamericano de México durante los años treinta, son visibles estas relaciones.

Antes de los años treinta, México había sido objeto de visiones reformistas; estas visiones previas fueron fértil terreno para el redescubrimiento por parte de los intelectuales neoyorquinos. Además del radicalismo del tipo de John Reed, estaba lo que Susman llama, en su análisis de los años treinta, el "redescubrimiento de la cultura". Parecía un fenómeno producido naturalmente por la profesionalización de las ciencias sociales y de la historia en Norteamérica. ${ }^{23}$ Los

${ }^{23}$ Entre la última década del siglo xIx y la primera del XX nacen como disciplinas limitadas al campo de los booming colleges y las universidades -y a un corpus teórico curricular definido- la antropología (con Lewin Henry Morgan) y la sociología (con Lester Ward). La historia, disciplina de lastrante pasado liberal, remonta sus orígenes académicos a mediados del siglo XIX, pero adquiere carácter más científico hasta la creación de la American Historical Society (1884). Véase Haskell, The emengence, 1977; Hofstadter, Anti-intellectualism, 1969; y Pery, Intellectual, 1984. 
trabajos de Ruth Benedith -en especial Patterns of culture, 1934- en plena depresión y desencanto de amplios sectores de la sociedad norteamericana, dieron a conocer un nuevo concepto de cultura que amplió lo que comúnmente se entendía por "alta cultura" o refinamiento. Esta nueva perspectiva consideraba la existencia de otras culturas llenas de valores comunitarios y humanitarios. Gradualmente, fue formándose una imagen pública de esas culturas, con, por ejemplo, Mexico: astudy of two Americas (1933) de Stuart Chase que fue un best seller. Lo que Chase logró, según Susman, fue poner en boca de todos un contraste del estudio de R. Redfield sobre Tepoztlán, con el sonado estudio antropológico de una comunidad norteamericana en proceso de transformación industrial, a saber, el trabajo de Helen y Robert Lynd: Middletown. Chase se mostró decepcionado por la industrialización, y fascinado con la imagen idealizada de un México comunitario y solidario. Al igual que hacían los populistas de la última década del siglo XIX, en las ciudades algunos intelectuales buscaban la comunidad perdida. México se convirtió en un lugar a observar. Los intelectuales mexicanos, a su vez, encontraron una ventana para su promoción. Diego Rivera ilustraba el libro de Chase, y el de C. Beals (Mexican maze, 1931). Miguel Covarrubias haría lo propio con el de Tannenbaum (Peace by revolution, 1933). En arte, Anita Brenner (Idols behind altars, 1929) descubrió para la izquierda norteamericana el arte mexicano. Todas estas visiones confirmaban una idealización de México que reencuentra a la comunidad, a la revolución ganada y al pueblo, con la necesaria frescura. De tal forma, cuando la izquierda neoyorquina buscaba salidas y ejemplos revolucionarios, ya existía un cuerpo de imágenes y discursos sobre Méxi- co. En la elaboración de ese cuerpo se había colado como inevitable invitada la tradición populista.

Al ser interpretado por los radicales neoyorquinos, que acabaron por constituirse en baluartes de la inteligencia norteamericana del siglo xx, México entró a formar parte de los enfrentamientos de la vida político-intelectual neoyorquina de los años treinta. ${ }^{24} \mathrm{Y}$ ahí se perdió. Así, pasó a ocupar un lugar entre las dicotomías existentes, por ejemplo, con respecto al pensamiento social norteamericano: pragmatismo liberal $v s$. marxismo: Dewey, Lynd, la revista The New Republic vs. Eastman, Edmund Wilson, Freeman, Tannenbaum y revistas como Quarterly Review, The Masses, primero y luego The New Masses. ${ }^{25}$ La posguerra dio el triunfo económico e ideológico al conservadurismo y el México idealizado sufrió dentro del desarrollo intelectual norteamericano la misma suerte que sus idealizadores: el olvido.

A partir de los años cuarenta, los elementos populistas y radicales fueron gradualmente negados, acoplados a una retórica más consensual, o forzados al

\footnotetext{
${ }^{24}$ No es hasta que su estudio se hiperacademiza, que México deja de estar inmerso en la discusión intelectual en sentido amplio, para quedar en manos de los expertos.

${ }^{25}$ Pells parece encontrar el mismo espectro, con otros extremos, en el arte y la literatura. Pero este espectro se define de acuerdo con un eje que tiene que ver con la labor propiamente artística, y otro con la política. Es decir, por un lado los esteticistas, si bien no partidarios de una pura posición de l'ant pour l'art, si orientados hacia una perspectiva simbólica experimental; por otro lado, los partidarios del realismo. Y conservadurismo y radicalismo, los extremos políticos. Así, hubo escritores realistas conservadores -Chase-, realistas radicales -John Dos Pasos- y los verdaderos genios por confesión radicales pero, afirma Pells, conservadores en esencia aunque plenos de originalidad-gente como Hemingway, Steinbeck o Wilson (véase Pells, $R a$ dical visions, 1973).
} 
olvido historiográfico. En cualquier interpretación histórica de los New York intellectuals, las nociones de "tradición americana" e "ideologías extrañas" entran en juego. Dentro de esos dos conceptos es donde se pierden las tradiciones radicales norteamericanas que, por ejemplo, son observables en el redescubrimiento de México. Las dicotomías antes mencionadas se presentan de distintas formas: la oposición entre teoría y práctica, ser individual-sociedad, cultura-civilización, l'art pour l'art, arte comprometido $y$, doctrinariamente, entre pragmatismo liberal $v s$. marxismo. La línea divisoria es la lejanía o cercanía a la "tradición americana". Por ello, a distancia, es relativamente sencillo organizar un espectro del desarrollo intelectual norteamericano, haciendo énfasis en su desradicalización, su natural derechización y sus tendencias al conservadurismo. Lo difícil es definir en qué consiste la tan traída y llevada tradición norteamericana: ¿una compleja construcción histórica? ¿Un casi ahistórico complejo tocquevilleano?

La tradición norteamericana entendida como abstracto de valores, se vuelve una atmósfera omniabarcante y omnipresente que, ni quienes están envueltos en ella, pueden definir. En cambio, la tradición norteamericana históricamente entendida parece contener valores -si es que de valores es de lo que ha de estar constituida-y experiencias contradictorias. Entre estos valores y experiencias se encuentran radicalismos populares que son tan de la tradición americana como el insigne cliché del apple pie.

\section{Del radicalismo a la academia}

Los intelectuales neoyorquinos se construyeron puertas para entrar a la "tradi- ción norteamericana". En ella, por ejemplo, encontraron lo que Freeman llamó "constante de materialismo" que incluía desde el pragmatismo filosófico norteamericano hasta el materialismo democrático de Walt Withman: "I accept reality, and dare not question it;/ materialism first and last imbuing/Hurrah forpositive science!/ long live demonstration." El materialismo marxista, para muchos intelectuales neoyorquinos, constituyó un sinónimo de objetividad científica, de verdad y progreso confiables. Y la certeza en la verdad objetiva formaba parte importante de la tradición intelectual sajona. Así, en el marxismo pudieron sentirse al mismo tiempo revolucionarios y norteamericanos. En la tradición norteamericana, estos intelectuales también encontraron un romanticismo a veces reformista, otras veces populista, que era acoplable a las exigencias revolucionarias de la época, así como a su propia herencia comunitaria como la de la villa ucraniana en que nació Freeman.

Así, el populismo norteamericano pudo ser acoplado por los intelectuales neoyorquinos como un punto de coincidencia, de entrada suya a la "tradición norteamericana". A su vez, el marxismo para ellos fue, por su materialismo y cientificidad, coincidente con el pragmatismo y el progresismo de Estados Unidos; y por su contenido utópico, vieron al marxismo como extensión del romanticismo populista. Sydney Hook, por ejemplo, en sus trabajos de los treinta buscaba hacer coincidir el pragmatismo a la Dewey con el pensamiento marxista, que desde su punto de vista parecía tan pragmático en su establecimiento de leyes como utópico-romántico en sus promesas revolucionarias. Por otra parte, para Freeman el encuentro con la revista The Masses fue también una forma de vincular tendencias: unión entre prag- 
matismo, romanticismo y revolución... Dice acerca de él mismo: "una lluviosa tarde, en un memorable local de la avenida Graham, el muchacho de 16 años en busca del cielo en la tierra encontró precisamente eso. Era justa (The Masses), bella y americana: Marx y Byron."

La interacción de estas dos entradas de los intelectuales judíos de Nueva York a la tradición norteamericana -el materialismo y el radicalismo populista- en parte explica el porqué de la desradicalización de la izquierda en Estados Unidos. Paradójicamente, si el cientificismo y el populismo fueron para los intelectuales neoyorquinos vínculos que les permitieron, al menos retóricamente, presentar su radicalismo de manera internacional -acorde con los movimientos de la época- y norteamericana -sin oponerse al american exceptionalism-, esos mismos elementos los llevaron a la vida universitaria. Ahí, la objetividad científica se convirtió en neutralidad científica y apoliticismo, y la inspiración populista en un rezago inevitable de no cientificidad, aunque sobrevivió, en los márgenes, como visión generalizadora. ${ }^{26}$ Por ello, los intelectuales que redescubrieron e idealizaron la realidad mexicana, también sirvieron de puente para la academización de la visión norteamericana de México.

Pocos de los intelectuales judíos lograron posiciones universitarias en los treinta, debido al antisemitismo institucionalizado. Sin embargo, F. Tannenbaum y Sydney Hook (Lionel Trilling

\footnotetext{
${ }^{26}$ Porque la desradicalización vía la academia puede ser explicada, como afirma Novick, como un temor a las masas: los intelectuales noryorquinos fueron: "onlyone generation removed from the east european 'sbtetl', where insurgent gentile peasants spelled pogrom" (pogrom: degüello y saqueo organizado especialmente contra los judíos en Rusia). Novick, That noble dream, 1988.
}

poco más tarde), entre otros, iniciaron desde tempranola vida universitaria. Con todo, como Christopher Lasch y Ellen Schrecker han probado, No ivory tower fue la academia norteamericana durante el macarthismo: varios académicos fueron expulsados por unamerican activities y la cacería de brujas existió casi en todas partes. Mil remociones sólo en Nueva York. Está fuera de moda, pero no hay que olvidar que el macarthismo fue factor importante en el proceso de desradicalización de la izquierda, incluso de aquella que se mantuvo como tal no obstante su academización.

El éxito económico de posguerra, la terrible herencia ideológica del holocausto, la movilidad social experimentada por la comunidad judía, los avatares del movimiento comunista internacional, el próspero filantropismo refomista norteamericano (a la Rockefeller)... todos son argumentos comunes en la explicación de la desradicalización del radical momentum neoyorquino de los años treinta. La academización de los intelectuales incluye un poco de todos estos factores. El hechoes que muchos intelectuales dejaron "la bohemia" por el salón de clases y de paso dejaron atrás toda su militancia. ${ }^{27}$ Paradójico: en tanto que la

27 Desde el punto de vista de lo político en ta academia, un camino prototípico es el de Sydney Hook quien, en julio de 1989 , muere no en el adusto Manhattan, sino en la plácida California: en el Hoover Institute of War and Peace, dentro de la Universidad de Stanford, think-thankconservador especializado en movimientos "subversivos" de todo el mundo. Viene a morir en California y termina sus días como parte del movimiento neoconservador porque para él estaba vivo el hilo de la tradición que va de William James y John Dewey a él. Defender la democracia liberal y el excepcionalismo norteamericano no es conservadurismo o defensa del status quo porque, como termina su últimoartículoen Partisan Review (1989), citando a su maestro de toda la vida John Dewey, en un mundo cambiante el status quo no existe. Pero 
academización merma el radicalismo de la visión norteamericana, también permite la supervivencia de corrientes relativamente radicales, como el populismo. Dado que más conocimiento especializado no produjo más entendimiento, se han vuelto necesarias aproximaciones históricas que permitan un mínimo de visión total y un contacto directo con la calle. Pero estas perspectivas han permanecido marginales y bien acomodadas dentro de la "metahistoria" fundamental: elexcepcionalismo liberal norteamericano.

Los intelectuales de izquierda se fueron academizando, y ya limpios de su pasado "oscuro", iniciaron una redefinición de la "tradición americana". El populismo entonces se convirtió sólo en una fuente inagotable de ideas demagógicas, racistas y retrógradas. El socialismo: un pecado de juventud. Ya limpios de estas culpas podían intentar construir de nuevo el excepcionalismo liberal norteamericano sobre bases más sólidas, y así lo hicieron autores como Hartzen The liberal tradition y Potter en People of plenty. En la academia, la inspiración populista tuvo que cubrirse con la parafernalia académica. Sin embargo, la escuela sembrada por Tannenbaum y su visión de México y Latinoamérica prueba que no obstante todo, la inspiración populista pudo vivir dentro del corsé de la academia. Pero su desarrollo ahora sigue - a pesar de los esfuerzos de la new left por resucitarla-, un cauce alejado de lo público y del devenir político del país: es una cuestión de expertos. ${ }^{28}$

otro ejemplo es Tannenbaum que logra innovar la estructura educativa de la Universidad de Columbia al introducir el sistema de seminarios, y quien no obstante sus muchos años de vida académica y del sosiego de su militancia política, la inspiración propueblo sembró con él firmes raíces académicas.

${ }_{28}$ Esto es parte de lo que en los años sesenta Hofstadter llamó "antiintelectualismo" norteameri-
Así, la visión norteamericana de México pasó de los ensayos -como las colecciones de Beals, Freeman y Tannenbaum-, a las monografias especializadas de los latin americanists. Sin embargo, la supervivencia de la inspiración populista en la academia, con sus problemas, al menos proporcionó una base ensayística general que provoca, propone y explica. No se equivoca Alan Knight, historiador inglés que edifica su impresionante análisis de la revolución mexicana sobre los cimientos de las sugerencias de Tannenbaum, al afirmar, refiriéndose a los estudios históricos de recientes generaciones de historiadores mexicanos: "...su giro académico 'objetivo y narrativo', ha probado que los estándares académicos no son por fuerza excluyentes de visiones más globales, de inspiraciones políticas populares y menos hipócritamente objetivas". ${ }^{29}$ Así, en Tannenbaum, la inspiración populista, con sus contradicciones, ha probado poder sobrevivir en la academia. El legado de Tannenbaum, a su vez, no está peleado con una imaginación disciplinada, ni con un uso, como dice Knight en The mexican revolution de un "controlado (no promiscuo) eclecticismo teórico".

Los intelectuales de Nueva York, como Tannenbaum, tradujeron $y / 0$ introdujeron a la academia una parte de la tradición radical norteamericana (el populismo) y, como Freeman, intentaron ser los ideólogos de una doctrina socialista a la norteamericana. En su éxito como traductores o en su fracaso -o arrepenti-

cano, y lo que Howe y Jacoby llama el fin de la bohemia, la desintelectualización de Estados Unidos (véase Hofstadter, Anti-intellectualism, 1969; Howe, A margin, 1982; Jacoby, The last, 1987).

${ }^{29}$ No por casualidad, el impresionante trabajo de Knight ha sido caracterizado por historiadores como D. Brading también como "a series of essays". Brading, "Reseña", 1987. 
miento- como ideólogos, mostraron las contradicciones del excepcionalismo norteamericano. Al no ser notadas, estas contradicciones nublan la contemplación, en el pasado y en el presente, de las posibles rutas alternativas del pensamiento norteamericano. Otros muchos intelectuales neoyorquinos desandaron sus pasos para desvanecer las huellas dejadas fuera del excepcional camino trazado para la historia de Norteamérica. Todo lo hicieron, hoy dicen los supervivientes, en nombre del convencimiento de y creencia en los "valores innatamente norteamericanos". ron fue darle cuerpo a un mito nacional que, si no estaba carente de contenido, sí estaba quedándose pequeño en el tamaño de las imágenes, valores e ideas que los tiempos exigían. Ellos ayudaron a darle fortaleza a todo aquello. Y en esto, su éxito es aún visible.

\section{Bibliografía}

El archivo personal de Freeman es localizable en el Hoover Institute of War and Peace (Stanford, California). En él, se encuentra interesante información sobre el movimiento comunista.

Contiene varios documentos sobre México -como cartas, borradores y notas de artículos, apuntes de viaje, transcripciones de entrevistas, etc. De ahí provienen la mayoria de las referencias de este ensayo. De especial interés es la polémica que este autor mantuvo con Diego Rivera acerca de los cambios sufridos por el mural del Palacio Nacional a lo largo de su producción, pues Joseph Freeman estuvo casado con lone Robinson, asistente de Rivera en los trabajos del Palacio Nacional (al respecto, consúltese I. Robinson, $A$ wall to paint on, Dulton, Nueva York, 1946). Los papeles personales de Frank Tannenbaum se encuentran en la Universidad de Columbia, Nueva York. No he tenido la oportunidad de consultarlos.

La ampliación y profundización de las ideas aquí propuestas requieren de la revisión de este material. Es proyecto a la vista.

-Beals, Carleton, Mexican maze, Filadelfia, 1931.

-Beard, Ch., The rise of american civilization, Macmillan, Nueva York, 1927.

-Bell, Daniel, The winding passage. Essays and sociological journeys, 1960-1980, Harvard University Press, Cambridge, 1980. , Marxian socialism in the United States, Princeton University Press, Nueva Jersey 1967.

-Bloom, Alexander, Prodigal sons: the New York intellectuals and their world, Nueva York, 1986.

-Brading, David, "Introduction: national politics and the populist tradition" en D. Brading (coord.), Caudillos and peasants in the mexican revolution, Cambridge University Press, Cambridge, 1980.

"Reseña de The mexican revolution de A. Knight", Journal of Latin American Studies, noviembre de1987, vol. XIX, t. 2.

-Brenner, A., Idols behind altars, Payson \& Clarke, Nueva York, 1929.

-Britton, J. A., Carleton Beals: a radical joumalist in Latin America, New Mexico University Press, Nuevo Mexico, 1987.

-Brown, J., "Exuberancia méxico-norteamericana 1920-1940", en Anglia, UNAM, México, 1968.

-Chase, Stuart, Mexico: a study of two Americas, Boston, 1933.

-Collins, Robert M., "The originality trap: Richard Hofstadter on populism", The Journal of American History, junio 1989, vol. LXXVI, núm. 1. 1981.

-Conovan, Margaret, Populism, Londres,

-Cooney, Terry A., The rise of the New York intellectuals: Partisan Review and its circle, Wisconsin, 1986.

-Croly, H., The promise of american life, Macmillan, Nueva York, 1912.

-Frank, Waldo, Memorias, introducción de A. Trachtenberg et al., trad. Eduardo Goligersay, Buenos Aires, 1975.

-Freeman, Joseph y Scott Nearing, Dollar 
diplomacy: astudy in american imperialism, Nueva York, 1925.

et al., Proletarian literature in

the United States: an antbology, Nueva York, 1937.

York, 1936. American testament, Nueva

-Genovese, Eugene, Thepoliticaleconomy of slavery, Nueva York, 1965.

-Goodwyn, L., The populist movement: a short bistory of the agrarian revolt in America, Nueva York, 1978.

-Greene, J. P., "Paine, America, and the 'modernization' of political consciousness", Political Sciences Quarterly, núm. 93, 1978.

-Hartz, L., The liberal tradition in America: an interpretation of american political thought since the revolution, Nueva York, 1955.

-Haskell, Th., The emergence of professional social science. The American Social Science Association and the nineteenthcentury crisis of autbority, University of Illinois Press, Chicago, 1977.

-Higham, J., Writing american bistory: essays on modern scholarship, Bloomington, 1970.

-Hobsbawm, E., The age of empire, 18751914, Nueva York, 1987.

The invention of tradition, Cambridge University Press, Cambridge, 1987.

-Hofstadter, R., The age of reform, Nueva York, 1955.

\section{was} , Anti-intellectualism in american life, Nueva York, 1969.

-Hook, S., "Curricula politics", Partisan Review, núm. 2, 1989.

Toward the understanding of Karl Marx, Nueva York, 1933.

Reason, social myths, and

democracy, Nueva York, 1940.

-Howe, Irving, A margin of bope, San Diego, 1982.

- "The culture of modemism", en The decline of the new, Nueva York, 1970.

-Jacoby, Russell, The last intellectuals: american culture in the age of academe, Nueva York, 1987.

-Kammen, M., Selvages and biases: the fabric of bistory in America, Nueva York, 1987.
-Knight, Alan, "Interpretaciones recientes de la revolución mexicana", en Secuencia, Instituto de Investigaciones Dr. José Maria Luis Mora, núm. 13, enero-abril de 1989, México. The mexican revolution, 2 vols., Cambridge University Press, Cambridge, 1985. -Lasch, Ch., "Consensus: an academic question?", The Journal of American History, vol. LXXVI, núm. 2, 1989.

"The cultural cold war: a short history of the Congress for Cultural Freedom", en Bernstein (comp.), Toward a new past. Dissention essays in american bistory, Pantheon Books, Nueva York, 1968.

-Lawrence, D. H., The plumed serpent, Quetzalcoatl, Martin Secker, Londres, 1926.

-Meyer, Eugenia, Conciencia bistórica norteamericana de la revolución mexicana de 1910, INAH, México, 1970.

-Mizruchi, Susan, The power of bistorical knowledge, Princeton University Press, Nueva Jersey, 1989.

-Muñoz Navarro, Antonio, Del populismo: breve exposición y examen de un gran proyecto de economía política para una nueva sociedad norteamericana, Imprenta del Gobiemo Federal, en el ex arzobispado, México, 1895.

-Novick, Peter, That noble dream: the objectivityquestion on the american bistorical profession, Cambridge University Press, 1988.

-Novo, Salvador, La vida en México en el periodo presidencial de Lázaro Cárdenas, Empresas Editoriales, México, 1964.

-Pells, Richard, The liberal mind in a conservative age: american intellectuals in the 1940's and 1950's, Nueva York, 1985. Radical visions and american dreams, Nueva York, 1973.

-Pery, Lewis, Intellectual life in America: a bistory, Chicago, 1984.

-Potter, David, People of plenty: economic abundance and the american character, Chicago, 1954.

-Schrecker, Ellen, No ivory tower: mccarthism in the university, Oxford University Press, Nueva York, 1986.

-Staughton, Lynd, Intellectuals origins of american radicalism, Pantheon Books, Nueva York, 1968. 
-Steinfels, Peter, The neoconservatives: the men who are changing America's politics, Simon and Schuster, Nueva York, 1979.

-Strout, Cushing, Making american tradition. Visions and revisions from Ben Franklin to Alice Walker, Rutgers University Press, New Jersey, 1990.

-Susman, Warren I., Culture as bistory: the transformation of american society in the twentieth century, Pantheon Books, Nueva York, 1984.

-Tannenbaum, Frank, The future of democracy in Latin America, Knopf, Nueva York, 1974.
Darker phases of the south, Nueva York, 1924. Mexican agrarian revolution, Macmillan, Nueva York, 1929. , Peace by revolution: an interpretation of Mexico, Nueva York, 1933. Mexico, the struggle for peace and bread, Knopf, Nueva York, 1950. , Balance of power in society and other essays, introducción por J. H. Randall, Macmillan, Nueva York, 1969.

-Trachtenberg, Alan, The incorporation of America: culture and society in the gilded age, Hill and Wang, Nueva York, 1982.
-Turner, F. J., The significance of sections in american bistory, $\mathrm{H}$. Holt, Nueva York, 1932.

-Tyrrell, lan, The absent Marx: class analysis and liberal bistory in 20tb-century America, Greenwood Press, Westport Conn., 1986.

-Wald, Alan M., The New York intellectuals: the rise and decline of the anti-stalinist left from the 1930 s to the 1980 s, University of North Carolina Press, Chapel Hill, 1987.

-Wiener, J. M., "Radical historians and the crisis in american history", The Joumal of American History, vol. LXVI, núm. 2, 1989.

-Wiles, P., "A syndrome, not a doctrine: some elementary theses on populism", en G. Ionesco y E. Gellner (comps.), Populism: its meaning and national characteristics, Macmillan, Nueva York, 1969.

-Woodward, Vann $C_{\text {., "The populist }}$ heritage and the intellectual", en Woodward, The burden of southern bistory, Baton Rouge, Nueva York, 1968.

Origins of the new south, 18771917, Louisiana State University Press, 1971. Thinking back: the perils of writing bistory, Louisiana State University Press, 1988. 